\title{
Temperature Distribution in the Insulation System of Condenser-Type HV Bushing-Its Effect on Dielectric Response in the Frequency Domain
}

\author{
Krzysztof Walczak * (D) and Jaroslaw Gielniak (D)
}

check for updates

Citation: Walczak, K.; Gielniak, J.

Temperature Distribution in the

Insulation System of Condenser-Type HV Bushing-Its Effect on Dielectric Response in the Frequency Domain. Energies 2021, 14, 4016. https:// doi.org/10.3390/en14134016

Academic Editor: Zhijin Zhang

Received: 11 June 2021

Accepted: 30 June 2021

Published: 3 July 2021

Publisher's Note: MDPI stays neutral with regard to jurisdictional claims in published maps and institutional affiliations.

Copyright: (c) 2021 by the authors. Licensee MDPI, Basel, Switzerland. This article is an open access article distributed under the terms and conditions of the Creative Commons Attribution (CC BY) license (https:// creativecommons.org/licenses/by/ $4.0 /)$.
Institute of Electrical Power Engineering, Poznan University of Technology, Piotrowo 3A, 60-965 Poznan, Poland; jaroslaw.gielniak@put.poznan.pl

* Correspondence: krzysztof.walczak@put.poznan.pl; Tel.: +48-61-665-2797

\begin{abstract}
HV bushings are an important part of the equipment of large power transformers, responsible for their many serious (including catastrophic) failures. Their proper exploitation needs to apply correct and reliable diagnostics, e.g., the use of dielectric response methods, that take into account their specific construction and working conditions. In this article, based on laboratory tests carried out on a real bushing, it has been shown that the significant temperature distribution within its core significantly affects the shape of the dielectric response of its insulation; therefore, the approach to its modeling should be changed. Hence, a new method for interpreting the results, using the so-called the $2 \mathrm{XY}$ model, is proposed. Subsequently, based on the measurements made on the insulators in operation, a new modeling method was verified. In conclusion, it can be stated that the 2XY model significantly improves the reliability of the dielectric response analysis, which should be confirmed in the future by tests on withdrawn and revised insulators.
\end{abstract}

Keywords: HV bushing; dielectric response; paper-oil insulation; temperature distribution

\section{Introduction}

The high voltage bushing is a device used to take a high electric potential lead out from a grounded housing such as a transformer tank. Due to its function, its insulation system is therefore exposed to the influence of a strong electric field (especially within the vicinity of its passage through a grounded metal housing) and generally works in two environments, often with different properties. For example, in a power transformer, the top part of the bushing is in the air and the bottom is in contact with the insulating liquid. Hence, in order correctly perform its function, devices of this type are required to have quite a complex structure. In the case of solutions for voltage above $30 \mathrm{kV}$, the bushings are equipped with specially designed screens that control the electric field distribution (condenser type bushing), between which there is an appropriately selected insulation. Likewise, due to its operations in different environments, the top and bottom parts of the insulator are significantly different. The overhead part is often more than three times longer than the lower oil part to ensure adequate surface electrical strength, and is protected by an additional cover that provides resistance to changing weather conditions. In turn, the lower oil part, aside from having to meet the requirements related to electrical strength, should also be resistant to the effects of an insulating liquid and have the appropriate heat resistance class. This is because the upper layer of the tank, where the bushing is located, has a relatively high temperature during transformer operation. An example of the construction of an RIP bushing (with Resin Impregnated Paper insulation) is shown in Figure 1 [1]. 


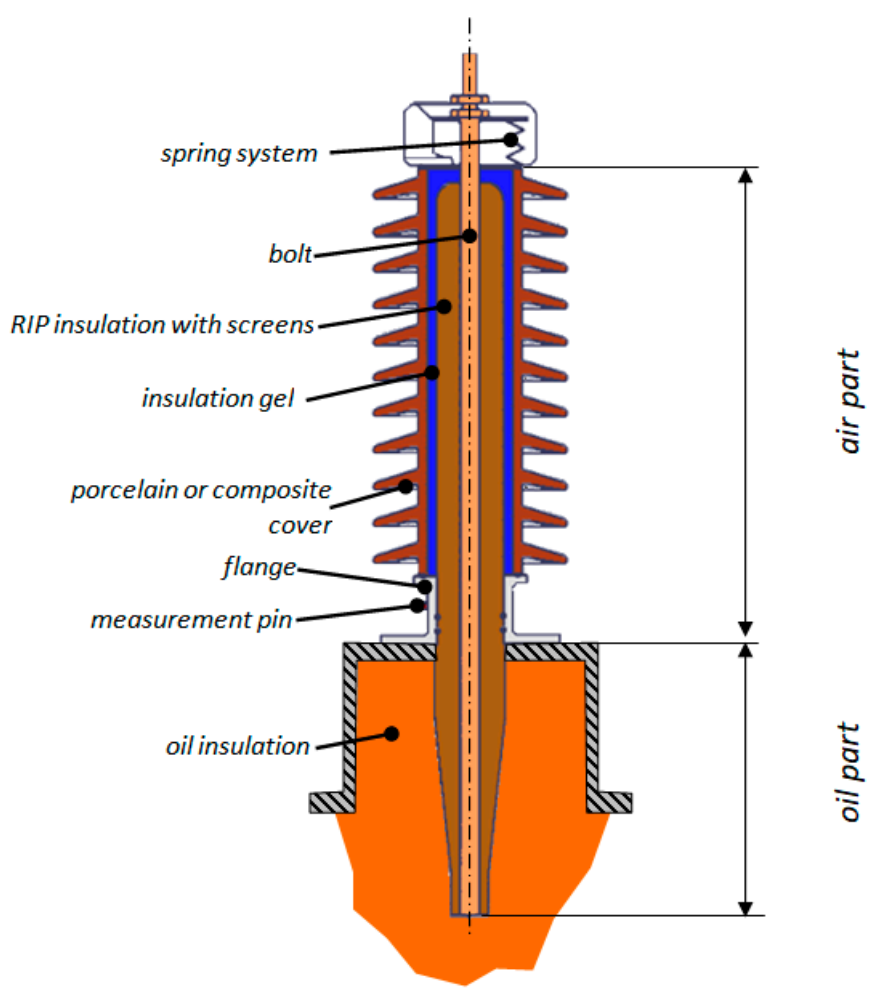

Figure 1. Cross-section of an RIP insulator.

Due to the difficult working conditions, transformer bushings for $110 \mathrm{kV}$ and more are characterized by a high risk of failure. A main cause of failure is dielectric damage (due to the electric or thermal breakdown of individual layers of insulation), as well as increased moisture resulting from leakage and progressive cellulose oxidation processes [2,3]. This is confirmed by the failure rate statistics, which are periodically published by relevant scientific groups, e.g., CIGRE or IEEE. An example of such an analysis can be found in the report "Transformer Reliability Survey" of the CIGRE Working Group A2.37 published in 2015 [4]. Based on a statistically large group of power transformers (536 network transformers and 127 GSU transformers), the main causes of failures and the factors that determined them were analyzed. These statistics show that for both network and unit transformers, bushing breakdown is a frequent cause of failures. According to the report cited above, these were the third largest cause of serious transformer failures and amounted to $17.16 \%$ for network transformers, and $16.53 \%$ for unit transformers (including insulators installed on the high and low voltage sides). Therefore, based on these statistics, it can be concluded that a bushing failure may have very serious, and in many cases even catastrophic, consequences for the entire device. The analysis of numerous cases shows that insulator damage is often also the cause of the entire transformer and the surrounding infrastructure catching fire, which in turn generates huge costs and causes serious environmental contamination. Figure 2 presents selected photos from the last few years where we can see examples of catastrophic power transformer failures, which were initiated by the damage of high voltage bushing. In each of the cases, the high-power transformers (from 160 to $240 \mathrm{MVA}$ ) were installed at power stations belonging to the national transmission network operator. The failed HV bushings ( 220 and $400 \mathrm{kV}$ ), were made using the OIP (Oil Impregnated Paper) technology. 


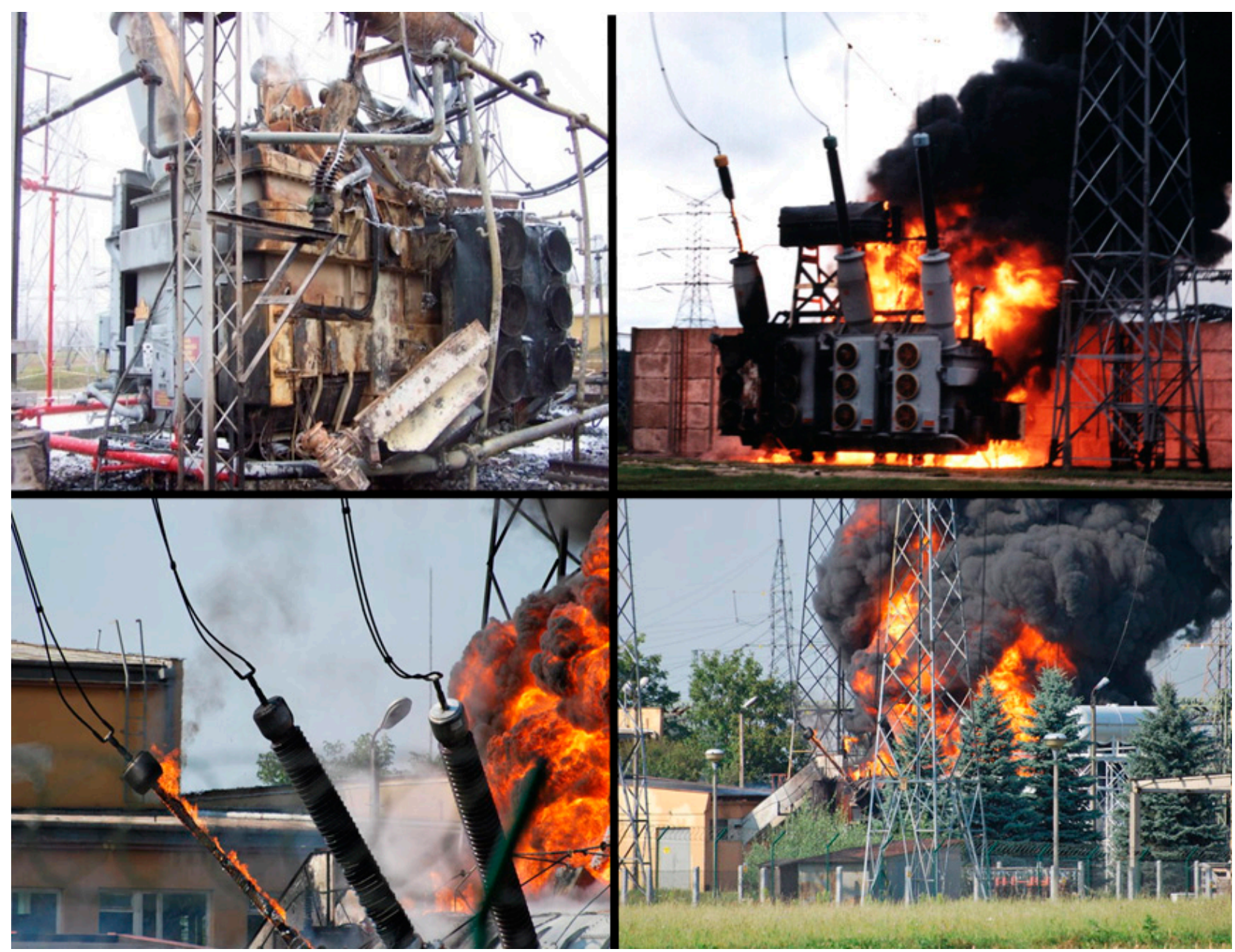

Figure 2. Examples of catastrophic failures of high power transformers initiated by the failure of a bushing.

Both the damage resulting from the degradation of the insulation and the increase in its moisture can be detected with the use of various diagnostic methods, including the so-called dielectric response methods [5]. Measurements of the dielectric response in the time or frequency domain have an advantage over traditional methods (e.g., measurement of tan delta and $\mathrm{C}$ at $50 \mathrm{~Hz}$ ) since they provide more complete information about the tested insulation material [6-9]. Owing to this more credible type of diagnosis, it is thus possible to observe the symptoms of upcoming failure in advance [10].

Despite the fact that the dielectric response methods are becoming more and more reliable, the interpretation of the obtained results is still difficult $[9,11-14]$. This is mainly due to the fact that the bushing works as a parallel system of two elements located in different environments, and the measured dielectric response is their resultant. The currently used algorithms (based on the $\mathrm{XY}$ model) for assessing the dielectric response often give an ambiguous result, frequently due to the poor fit of the measurement curve to the model curve. In a situation where an obtained value, such as moisture, is close to the criterion value, this will be of great importance when making a decision about its further use or replacement, which in turn is a complicated and costly process.

The 2XY model proposed in this article, developed on the basis of laboratory and field measurements, is an interesting alternative to the traditional approach in assessing the condition of the bushing. It seems that in many cases it will increase the reliability of the obtained analysis results, which in turn will translate into a reduction in the number of transformer failures.

This article presents laboratory test results of a $110 \mathrm{kV}$ insulator made using the OIP (Oil Impregnated Paper) technology. The insulator was subjected to uniform and 
non-uniform heating in order to observe the influence of temperature and its distribution on the dielectric response of the insulation system. Based on the obtained results, a new method of dielectric response modeling (2XY model) was developed in order to obtain a reliable method for assessing the degree of degradation and moisture content of the solid insulation in various types of bushings. Finally, the new method for interpreting the insulation dielectric response was verified on a few selected bushings in operation.

\section{Materials and Methods}

For the experimental tests, a Trench transformer bushing, model COT-250-800, was used (Figure 3a). It is an insulator made using the OIP technology, which means that the core is a paper insulation impregnated with a special liquid based on mineral oil. The bushing is equipped with screens made of aluminum foil that control the distribution of the electric field. The cover of the oil-paper insulation is made of porcelain. The head, containing the degassed liquid that fills the insulator, is equipped with an oil level indicator. The bushing was designed for $52 \mathrm{kV}$ rated voltage, $800 \mathrm{~A}$ current, and $250 \mathrm{kV}$ impulse withstand voltage.

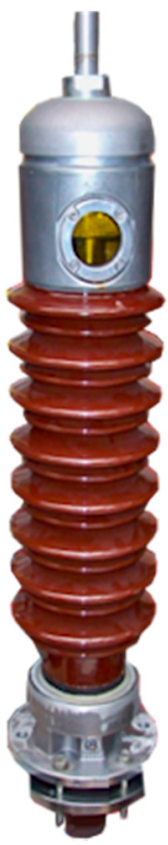

(a)

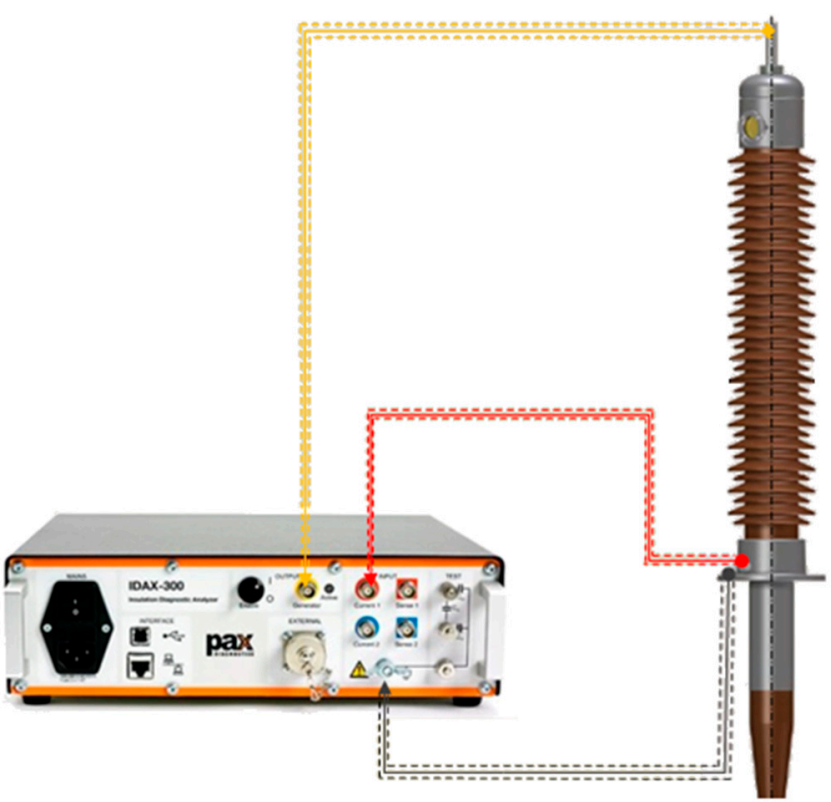

(b)

Figure 3. COT-250-800 Trench transformer bushing (a), method for connecting the test bushing to the IDAX $300 \mathrm{~m}(\mathbf{b})$.

The bushing insulation dielectric response was measured using the IDAX 300 insulation diagnostic system from PAX Diagnostics. The connection system of the bushing with the IDAX $300 \mathrm{~m}$ is shown in Figure $3 \mathrm{~b}$. The measurements were performed in the frequency range of $0.001-1000 \mathrm{~Hz}$, at a voltage of $200 \mathrm{~V}$.

During the tests, temperature sensors were attached to the bushing, the arrangement of which is shown in Figure 4a. The sensors allowed us to control the temperature distribution and the heating of individual parts of the insulator during the experiment. The probes used to measure the temperature were thermocouples with a J-type connector $(\mathrm{Fe}-\mathrm{CuNi})$, the limit error of which, according to the manufacturer's specification, was $\pm 1.5^{\circ} \mathrm{C}$. To be sure, the sensors' indications were previously verified through a test in a thermal chamber, performed in accordance with the standard [15]. In order to be able to control the temperature of the test object, the upper part of the insulator was placed within a glass pipe, and the lower part was immersed in a glass vessel filled with oil. The temperature of the object in the upper part was changed with the use of a fan heater, while in the lower 
part, the temperature was modified with the help of a heater with a magnetic stirrer. The arrangement of the temperature control systems is shown in Figure $4 b$.

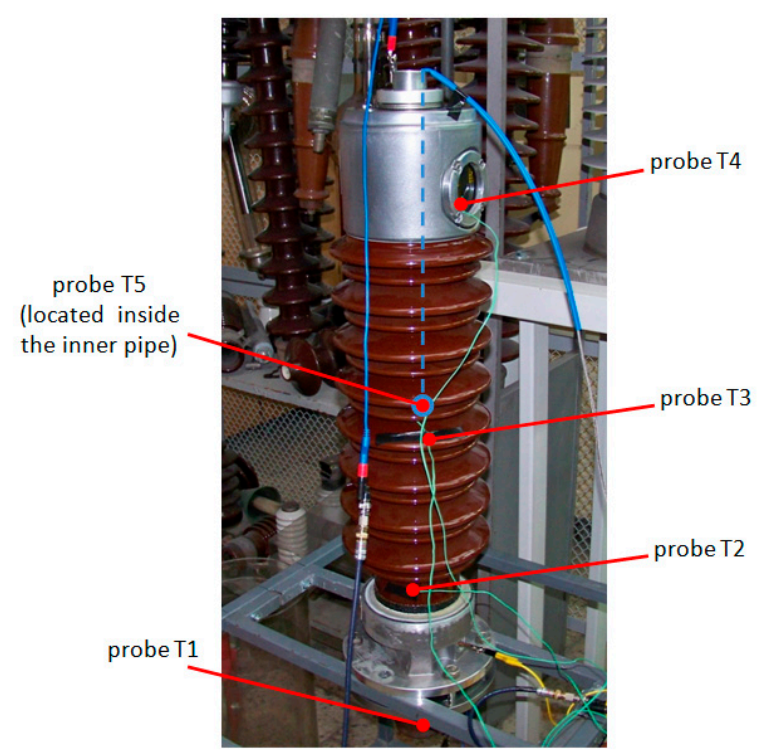

(a)

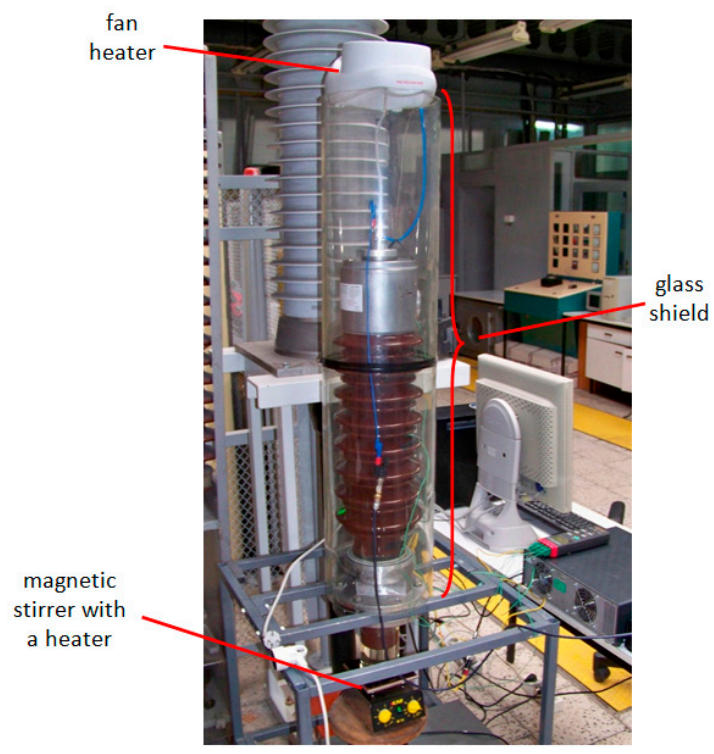

(b)

Figure 4. Arrangement of temperature sensors (a); insulator heating system (b).

The research methodology adopted in the experiment was as follows: First, the measurements of the dielectric response $(\tan \delta=f(f))$ of the bushing insulation were performed under thermal equilibrium conditions, at room temperature $\left(23^{\circ} \mathrm{C}\right)$. This result was used as a reference in further studies. Subsequent tests included the uniform heating of the system to the temperatures $30^{\circ} \mathrm{C}$ and $40^{\circ} \mathrm{C}$, and unevenly forcing the lower oil part of the bushing to $50^{\circ} \mathrm{C}$ and $60^{\circ} \mathrm{C}$, while maintaining an open temperature range for the air part (the room temperature was then $23^{\circ} \mathrm{C}$ ). The individual test variants and the adopted temperatures of the oil and air parts of the bushing are presented in Table 1. The adopted temperature ranges correspond to the real operating conditions that occur in real power transformers in the summer season.

Table 1. Summary of cases examined during the experiment.

\begin{tabular}{ccc}
\hline & Temperature $\left({ }^{\circ} \mathbf{C}\right)$ & \\
\hline${\text { Case } \mathbf{N}^{\circ}}_{1}$ & Oil & Air \\
\hline 2 & 23 & 23 \\
3 & 30 & 30 \\
4 & 40 & 40 \\
5 & 50 & 23 \\
\end{tabular}

\section{Results}

\subsection{Measurements with Uniform Temperature Distribution}

In the first part of the experiment, measurements were carried out at different insulation temperatures, but with a uniform temperature distribution throughout the bushing. According to the data presented in Table 2, the average object temperatures during the measurements were $23.1{ }^{\circ} \mathrm{C}, 30.1^{\circ} \mathrm{C}$, and $40.7^{\circ} \mathrm{C}$. 
Table 2. Measurement of the bushing temperature at various points to check for uniform temperature distribution; the markings of the measurement points are as shown in Figure 4a.

\begin{tabular}{cccc}
\hline \multicolumn{3}{c}{ Temperature $\left({ }^{\circ} \mathbf{C}\right)$} & \\
\hline Sensor $\mathbf{N}^{\circ}$ & Case 1 & Case 2 & Case 3 \\
\hline 1 & 22.7 & 30.4 & 40.4 \\
2 & 22.7 & 28.3 & 37.9 \\
3 & 22.9 & 29.6 & 40.7 \\
4 & 23.2 & 30.5 & 43.1 \\
5 & 23.8 & 31.3 & 41.3 \\
Average & 23.1 & 30.1 & 40.7 \\
\hline
\end{tabular}

After the proper preparation of the system and the connection of the measuring equipment as shown in Figure 3b, measurements of the dielectric response in the frequency domain were carried out, which is reflected in the characteristic $\tan \delta=f(f)$. The individual results, for comparison purposes, are shown in one collective diagram presented in Figure 5. The obtained result is typical for a new OIP-type insulator. Comparing the individual characteristics, it can be seen that as the insulation temperature increases, they do not change their shape but rather shift to the higher frequencies, which is a typical effect described by the Arrhenius law [16]:

$$
\tan \delta_{1}=\tan \delta_{2} \exp \left[\frac{A_{e}}{k} \cdot\left(\frac{1}{273-T_{1}}-\frac{1}{273-T_{2}}\right)\right],
$$

where:

- $\quad \tan \delta$-loss tangent;

- $\quad A_{e}$-activation energy;

- $\quad$-temperature;

- $\quad K$-Boltzman's constant.

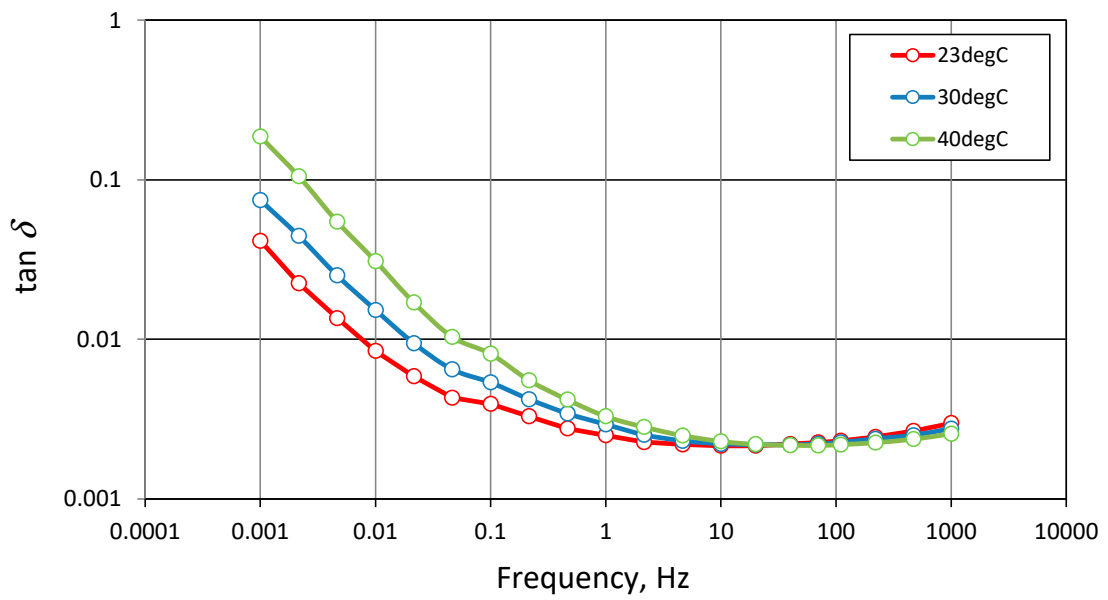

Figure 5. Dielectric response of the bushing insulation with uniform temperature distribution; measurements made for temperatures: $23^{\circ} \mathrm{C}, 30^{\circ} \mathrm{C}$, and $40^{\circ} \mathrm{C}$.

Assuming the activation energy typical for the paper-oil insulation system, i.e., $0.9 \mathrm{eV}$ [17-19], and converting the individual dependencies to the temperature of $23^{\circ} \mathrm{C}$ (Figure 6), one can see that the characteristics perfectly overlap. Therefore, despite the existence of two significantly different media (air and oil), the system behaves very homogeneously; therefore, it should be assumed that with small differences in object temperature during the measurements, there will be no difficulties with modeling the system and interpreting the obtained results (e.g., determining the degree of moisture content). The method of modeling and analyzing such systems will be described in more detail in Section 4.1. 


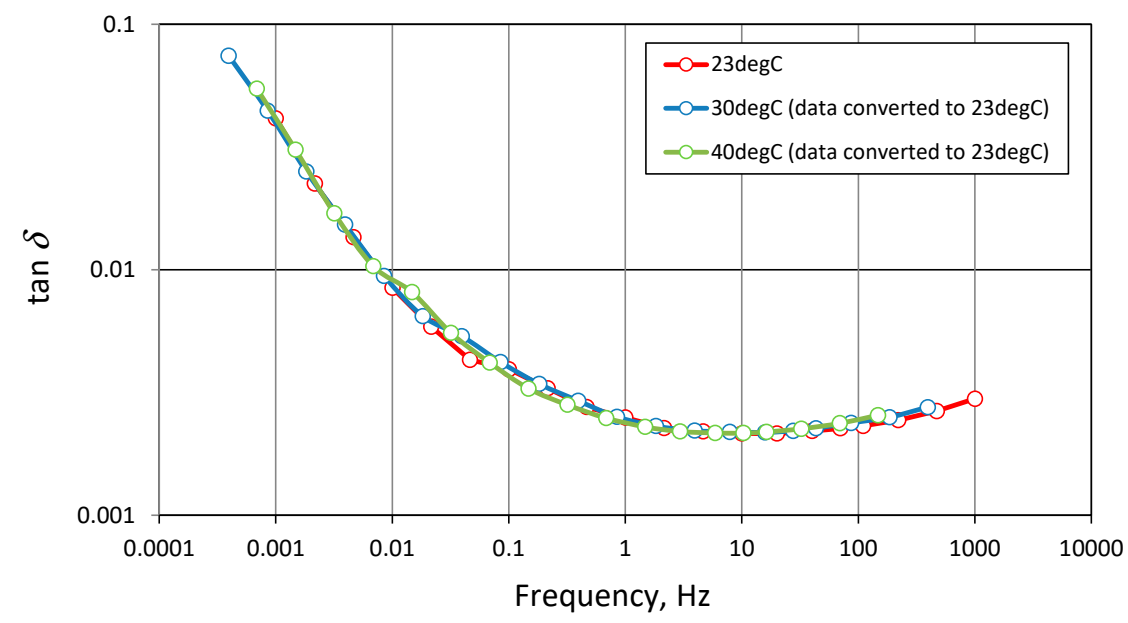

Figure 6. Dielectric response of the bushing insulation with uniform temperature distribution; measurements made for temperatures: $23^{\circ} \mathrm{C}, 30^{\circ} \mathrm{C}$, and $40{ }^{\circ} \mathrm{C}$, subsequently converted to $23^{\circ} \mathrm{C}$, assuming activation energy at the level of $0.9 \mathrm{eV}$.

\subsection{Measurements with Nonuniform Temperature Distribution}

In the second part of the experiment, measurements were carried out to simulate the situation of nonuniform temperature distribution, which was obtained by forcing different operating conditions on the air and oil part of the bushing. According to the data presented in Table 3, in both cases, the air part was operated at an ambient temperature of approximately $23^{\circ} \mathrm{C}$, and the oil part was heated to a temperature of $50{ }^{\circ} \mathrm{C}$ and 60 ${ }^{\circ} \mathrm{C}$, respectively. The temperature distribution was obtained after $2 \mathrm{~h}$ of the heating system operation.

Table 3. Measurement of the bushing temperature at various points to check for non-uniform temperature distribution; the markings of the measurement points are as shown in Figure 4a.

\begin{tabular}{ccc}
\hline & Temperature $\left({ }^{\circ} \mathbf{C}\right)$ & \\
\hline Case $\mathbf{N}^{\circ}$ & Case 4 & Case $\mathbf{5}$ \\
\hline Oil & 50.0 & 60.1 \\
1 & 25.4 & 29.2 \\
2 & 23.6 & 25.1 \\
3 & 23.5 & 25.1 \\
4 & 23.7 & 25.2 \\
5 & 25.2 & 30.4 \\
\hline
\end{tabular}

For comparison purposes, the individual results are shown in one collective graph in Figure 7. Analyzing the characteristics, it can be noticed that this time the temperature change caused not only a curve shift towards higher frequencies, but also a change of its shape. This can be seen by converting the obtained results to the same temperature level (according to the Arrhenius law mentioned above). The result of conversion is presented in Figure 8. At the shift, the activation energy was assumed at the level of $0.9 \mathrm{eV}$ and the object temperature was an average value calculated from temperature measurements by individual sensors (Table 3). The shifted curves do not match as well as they did in the case of the uniformly heated bushings, despite the fact that the average values of the temperatures obtained in individual cases do not differ significantly (within $9{ }^{\circ} \mathrm{C}$ ). 


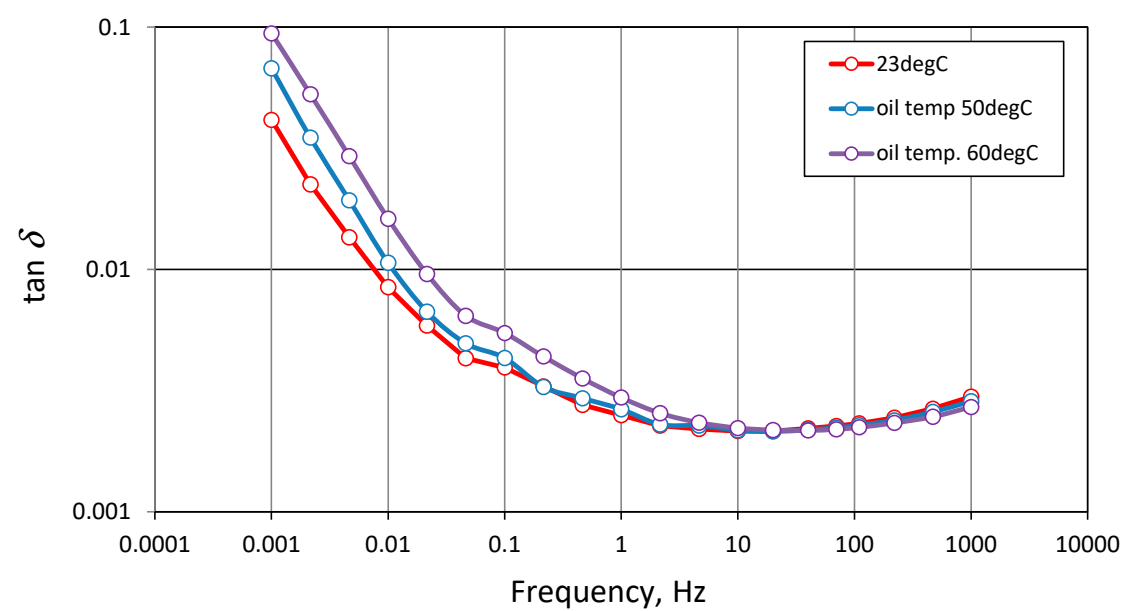

Figure 7. Dielectric response of the bushing insulation with non-uniform temperature distribution; measurements made at an ambient temperature of $23^{\circ} \mathrm{C}$; temperature of the oil part at $50{ }^{\circ} \mathrm{C}$ and $60{ }^{\circ} \mathrm{C}$.

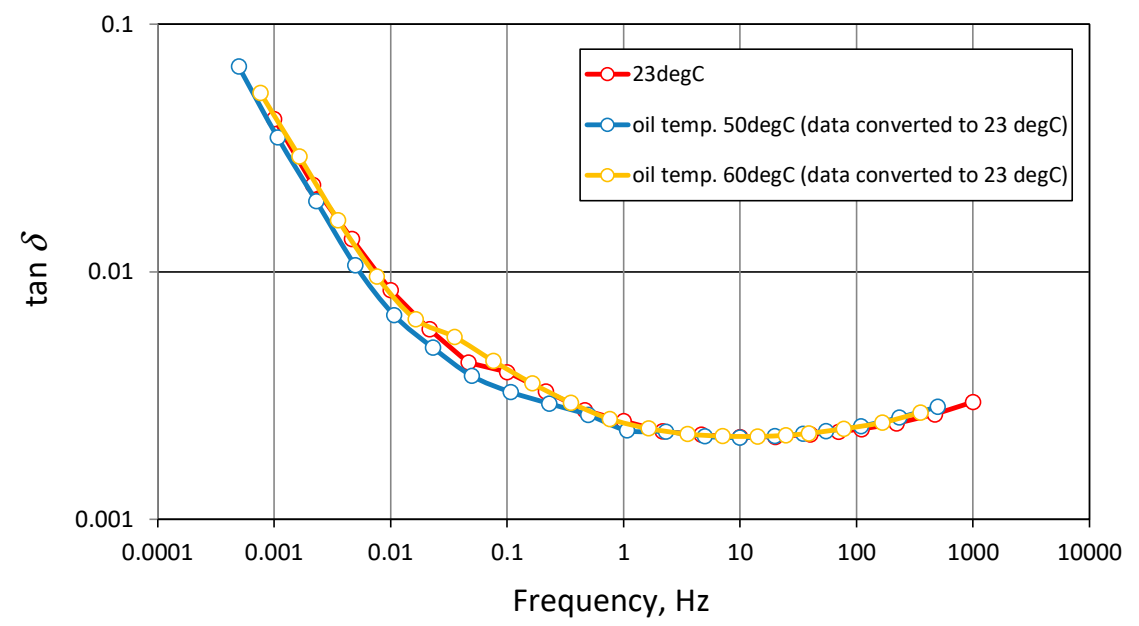

Figure 8. Dielectric response of the bushing insulation with non-uniform temperature distribution; measurements made at an ambient temperature of $23{ }^{\circ} \mathrm{C}$; the temperature of the oil part was at $50{ }^{\circ} \mathrm{C}$ and $60^{\circ} \mathrm{C}$, subsequently converted to $23^{\circ} \mathrm{C}$, assuming an activation energy at the level of $0.9 \mathrm{eV}$.

Summarizing the obtained results, several conclusions can be drawn. Firstly, the nonuniform temperature distribution changes the shape of the $\tan \delta=f(f)$ characteristic, which will certainly make the process of modeling and assessing the condition of the bushing's paper-oil insulation more difficult in the traditional way, i.e., assuming one resultant temperature. It should be emphasized that the tested insulator had a relatively large disproportion between the oil and air parts (in the ratio 1:4), which means that the temperature distribution was characterized by a sizeable gradient and was largely dominated by the ambient temperature. It should be expected that in the case of insulators for higher voltage (from $110 \mathrm{kV}$ and higher), for which the proportions are different, the observed effect will be even stronger. In addition, it should also be noted that the tests were carried out on a new insulator, with dry and non-degraded insulation, which made it more homogeneous. In the case of insulators with a long service life and in which degradation processes have already occurred, the dielectric properties of the bushing will have already changed and may consequently affect the resultant dielectric response of the device. The influence of these factors, confirmed by the measurements made on insulators in service, will be presented in Section 4.2. 
After analyzing the results of the studies presented above, and owing to their years of experience in the practice of high voltage bushing diagnosis, the authors were prompted to verify the standard approach in the interpretation of measurements of the dielectric response of bushing insulation; consequently, the authors were inspired to develop a new modeling method, which will improve the reliability of assessments of these important elements of transformer equipment. The developed concept and its verification will be discussed in the following sections of the article.

\section{Discussion}

\subsection{Modeling the Dielectric Response of the Bushing Insulation in the Case of Significant} Temperature Distribution along Its Axis

The basis for the interpretation of the results in the DFR (Dielectric Frequency Response) method is the comparison of the dielectric response obtained from the measurements (e.g., the relationship $\tan \delta=f(f)$ ) with the response of the model based on previously determined reliable moisture patterns [20]. The so-called XY model [21-24], where the parameters $X$ and $Y$ determine the percentage of cellulose insulation in the celluloseoil insulation system (Figure 9), is a commonly used analysis tool, described in many publications such as in [25-27].

a)

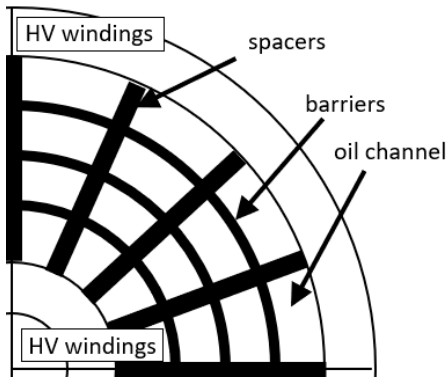

b)

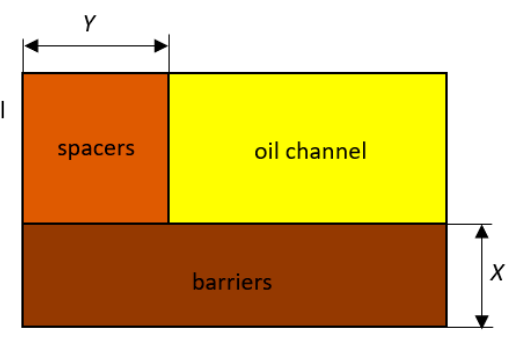

Figure 9. A portion of the transformer insulation cross-section, with a cylindrical arrangement of windings (a) and a simplified transformer insulation model (b).

In this model, information about the geometry of the insulating system as well as information on the conductivity and electric permeability of the insulating liquid and the object temperature are required. Therefore, the credibility of the obtained result will largely depend on whether the correct parameters for the model [28] are adopted. Most of the geometric and material parameters can be determined quite precisely in the process of matching the measurement curve to the model curve; however, use of the appropriate moisture standards and the adoption of the correct temperature are necessary [29].

Moisture patterns are presented as components of real and imaginary permittivity, depending on the voltage frequency for the selected level of moisture in the cellulose insulation and the selected temperature. They are usually available as a part of an analytical software, included by the manufacturer of the measuring apparatus.

However, determining the proper temperature of the object, despite its relatively small dimensions compared to the dimensions of the power transformer, may pose some difficulties. As it was proved earlier in the article, a bushing working in two environments very often has a significant temperature distribution along its axis, i.e., the temperature in the overhead section can be much lower than in the oil section. In this case, in order to model the insulation system, a resultant temperature should be assumed. Some guides suggest assuming a temperature that is two-thirds of the ambient temperature and onethird of the temperature of the upper oil layer [30]. Such an approximation produces relatively good results, provided that the temperature of the overhead and oil portions are not significantly different. However, a much better representation can be obtained if the mathematical model is modified by treating the overhead and oil parts of the bushing as 
two insulation systems connected in parallel (Figure 10). The 2XY model proposed by the authors therefore represents the dielectric loss factor measured between the line terminals $Z_{1}$ and measuring terminals $Z_{2}$ of the insulator. In the model thus defined, the XY1 block (overhead part) and the $\mathrm{XY} 2$ block (oil part) can be assigned the actual temperature, as well as separate geometric and material parameters, consistent with the construction of the bushing.
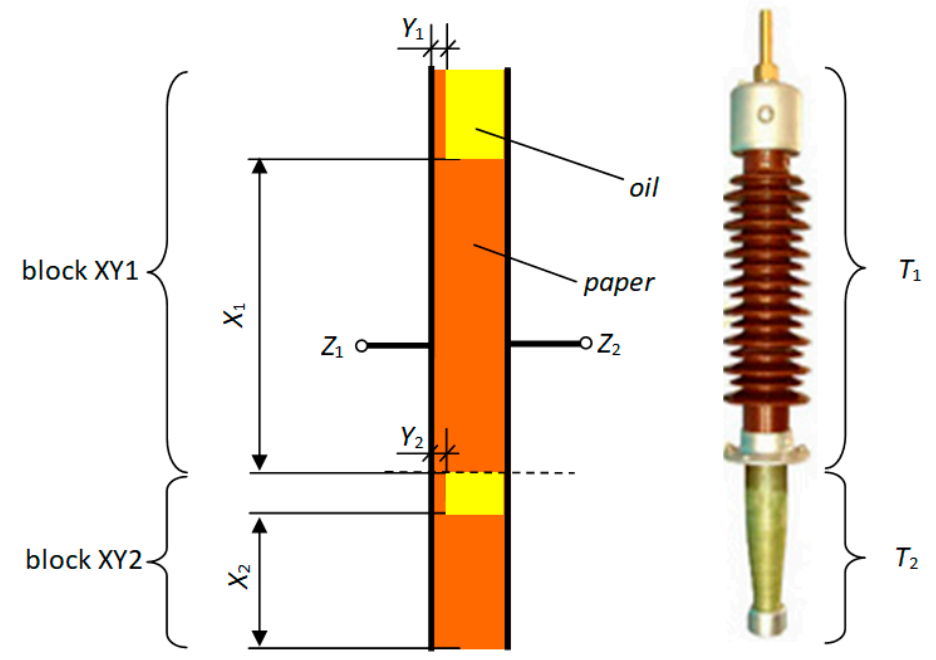

Figure 10. The $2 X Y$ model representing a bushing whose overhead part (block XY1) is at temperature $T_{1}$, and oil part (block XY2) is at temperature $T_{2}$.

For each area representing a part of the insulation of a different temperature ( $T_{1}$ and $T_{2}$ ), complex permittivity is calculated according to the following formulae:

$$
\begin{aligned}
& \varepsilon_{X Y_{1}(\omega, T)}^{*}=X_{1} \varepsilon_{P(\omega, T)}^{*}+\frac{1-X_{1}}{\frac{1-Y_{1}}{\varepsilon_{U(\omega, T)}^{*}}+\frac{Y_{1}}{\varepsilon_{P(\omega, T)}^{*}}} \\
& \varepsilon_{X Y_{1}(\omega, T)}^{*}=X_{2} \varepsilon_{P(\omega, T)}^{*}+\frac{1-X_{2}}{\frac{1-Y_{2}}{\varepsilon_{U(\omega, T)}^{*}}+\frac{Y_{2}}{\varepsilon_{P(\omega, T)}^{*}}}
\end{aligned}
$$

where:

- $\quad \varepsilon^{*} P(\omega, T)$-complex permittivity of paper impregnated with mineral oil;

- $\quad \varepsilon^{*} U(\omega, T)$-complex permittivity representing areas of the leakage nature (oil, shield);

- $\quad X_{1}, Y_{1}, X_{2}, Y_{2}$ - geometric parameters describing the participation of the paper in the whole modeled space.

Subsequently, for each area, the tangent of the dielectric loss angle is determined according to the following formulae:

$$
\begin{aligned}
& \tan \delta_{X Y 1}=\frac{\varepsilon^{\prime \prime} X Y_{1}}{\varepsilon^{\prime} X Y_{1}} \\
& \tan \delta_{X Y 2}=\frac{\varepsilon^{\prime \prime} X Y_{2}}{\varepsilon^{\prime} X Y_{2}}
\end{aligned}
$$

where:

- $\quad \varepsilon_{X Y_{1}}^{\prime}, \varepsilon_{X Y_{2}}^{\prime}$-the real part of permittivity calculated respectively for the areas of temperatures $T_{1}$ and $T_{2}$ according to Formulae (1) and (2);

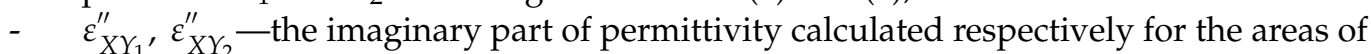
temperatures $T_{1}$ and $T_{2}$ according to Formulae (1) and (2). 
The tangent of the dielectric loss angle is calculated for the whole insulator at the final stage, according to the formula:

$$
\tan \delta_{2 X Y}=A \tan \delta_{X Y 1}+(1-A) \tan \delta_{X Y 2}
$$

where:

- $A$-participation of the area of temperature $T_{1}$ in the whole volume of the insulator; - $\quad \tan \delta_{X Y 1}, \tan \delta_{X Y 2}$-tangent of the dielectric loss angle of the areas of temperatures $T_{1}$ and $T_{2}$.

Figure 11 shows exemplary curves obtained from mathematical modeling for blocks $X Y 1$ and XY2 and the resultant curve for connected blocks XY1and XY2. The measurement points are plotted on the result curve. As you can see, the good fit of the XY1 $\mathrm{XY} 2$ model curve as well as the measurement points prove that the methodology is correct. Using the described approach, it is possible to determine the moisture content of the bushing cellulose insulation with sufficient accuracy; this will be analyzed in the next section using the results of field measurements.

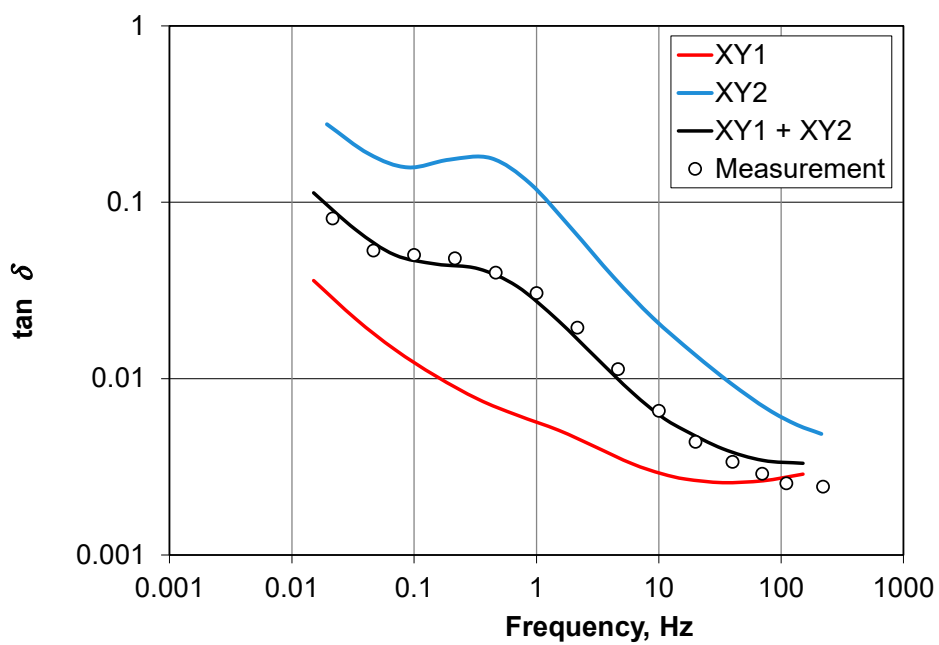

Figure 11. Loss tangent for $220 \mathrm{kV}$ voltage insulator, Hitachi type OS, measured and modelled using the $2 X Y$ model, taking into account the axial temperature distribution. Upper part temperature, $8^{\circ} \mathrm{C}$; oil temperature in the upper layer, $29^{\circ} \mathrm{C}$.

\subsection{Verification of the $2 X Y$ Model on Insulators in Service}

In order to verify the proposed $2 X Y$ model, measurements on bushings in service were carried out. Bushing insulators, due to their high impedance, i.e., low capacitance and high resistance, are difficult elements in terms of providing information on the dielectric response and therefore require the use of an additional high-voltage amplifier, as shown in Figure 12. The equipment used for the tests are the insulation response analyzer (IDAX 300) and a VAX type amplifier supplied by PAX Diagnostic. The VAX-020 amplifier enabled measurements at voltages up to $1400 \mathrm{~V}_{\mathrm{RMS}}$ in the frequency range from $10^{-4} \mathrm{~Hz}$ to $10^{3} \mathrm{~Hz}$. 


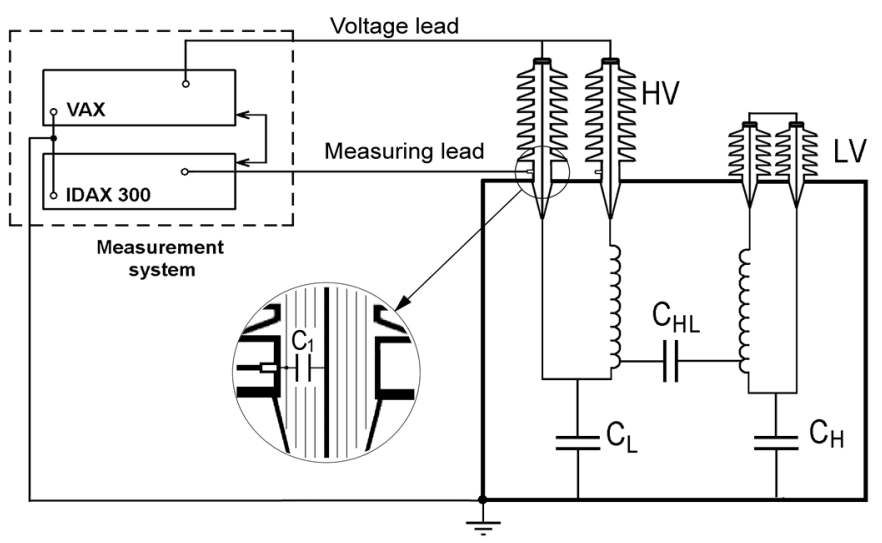

Figure 12. Test system for the measurement of the dielectric response of bushings.

The presented research concerns the measurements of the capacitance of bushing insulators equipped with a measuring tap. The UST (Ungrounded Specimen Test) system was used, in which the voltage lead is connected to the line clamps, and the measuring lead to the measuring tap. In such a configuration (Figure 12), only the capacitance $C_{1}$ of the bushing is measured $\left(\mathrm{C}_{\mathrm{HL}}, \mathrm{C}_{\mathrm{H}}\right.$, and $\mathrm{C}_{\mathrm{L}}$ capacitances are not measured and the influence of leakage current flowing on the outer surface of the insulator is eliminated).

Figures 13-15 show examples of dielectric response $(\tan \delta=f(f))$ modelling using the classic XY model and the $2 \mathrm{XY}$ model for three different bushing types. In the lower part of each of these figures, the relative differences between the measured values and those calculated with the $X Y$ and $2 X Y$ models are shown in the form of bars. The parameters $(X$, $Y$, oil conductivity, moisture in paper insulation) resulting from the application of the $X Y$ model were obtained using the standard auto-matching procedure implemented in the MODS program, which is the measuring device used. So far, no IT tool has been developed that could similarly search for parameters for the 2XY model; hence, the adjustment process was performed manually. However, in order for the procedure to be repeatable, an algorithm was used to minimize the error. From the outset, it was assumed that the geometry of individual blocks (air and oil) may change slightly due to the specificity of the measuring system and because it is largely determined by paper insulation, thus the filling is close to $100 \%$. After adopting the geometry of the system and selecting the appropriate temperature for individual parts of the model, conductivity and moisture were introduced to adjust the curves and minimize the value of the $M_{A D M}$ parameter (Mean of the Absolute Difference Modules, defined below). The process was repeated until the minimum value of the criteria parameter was obtained. 

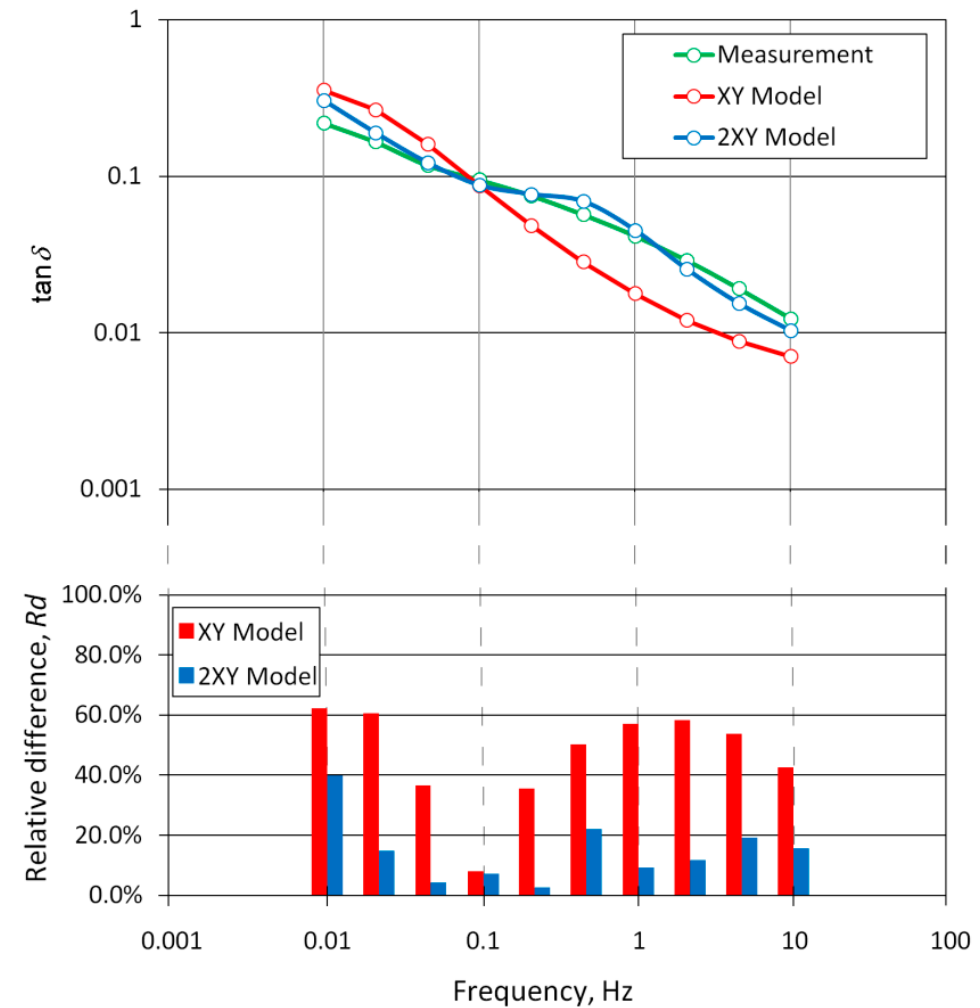

Figure 13. The dependence of the loss tangent on the frequency, measured for the COT type $\left(U_{n}=142 \mathrm{kV}\right)$ bushing insulator and calculated based on the XY and $2 \mathrm{XY}$ models, with the calculated relative differences between the measured and calculated values for both models.

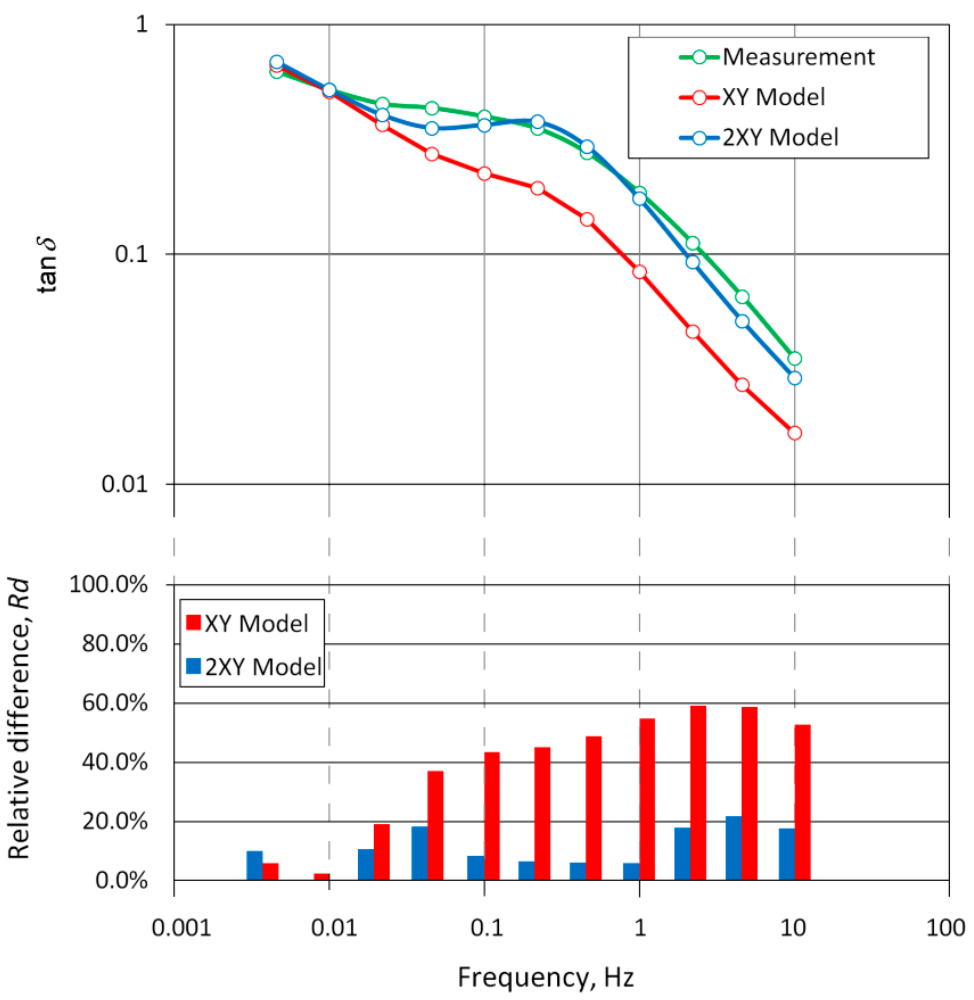

Figure 14. The dependence of the loss tangent on the frequency, measured for the OS type $\left(U_{n}=110 \mathrm{kV}\right)$ bushing insulator and calculated based on the XY and 2XY models, with the calculated relative differences between the measured and calculated values for both models. 


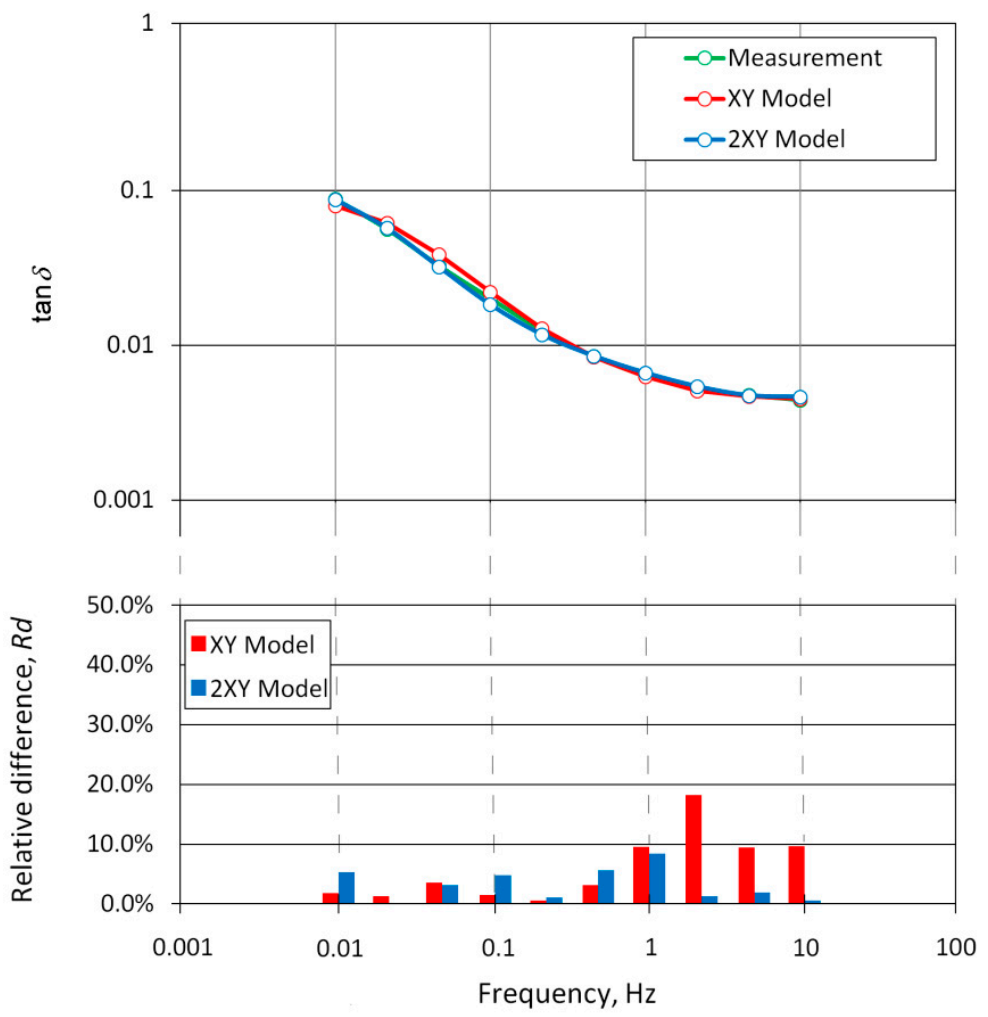

Figure 15. The dependence of the loss tangent on the frequency, measured for the COT type $\left(U_{n}=220 \mathrm{kV}\right)$ bushing insulator and calculated based on the XY and 2XY models, with the calculated relative differences between the measured and calculated values for both models.

The mean of the absolute difference modules $\left(M_{A D M}\right)$ was used as a first quantity to assess the quality of the curve fitting obtained from modelling and measurement. The $M_{A D M}$ value can be calculated from the equation:

$$
M_{A D M}=\frac{\sum_{i=1}^{n}\left|\frac{\tan \delta_{m_{i}}-\tan \delta_{f_{i}}}{\tan \delta_{m_{i}}} \cdot 100 \%\right|}{n},
$$

where:

- $\quad \tan \delta_{m}$-loss tangent measured for a specific frequency;

- $\quad \tan \delta_{f}$-loss tangent calculated for a specific frequency based on XY or 2XY model;

- $\quad n$-number of points for which measurements and calculations were carried out.

The second quantity we use to assess the quality of the fitting is the correlation coefficient $(r)$. The correlation coefficient was calculated according to the formulae [31]:

$$
r=\frac{\sum_{i=1}^{n}\left(\tan \delta_{m_{i}}-\overline{\tan \delta_{m}}\right)\left(\tan \delta_{f_{i}}-\overline{\tan \delta_{f}}\right)}{\sqrt{\sum_{i=1}^{n}\left(\tan \delta_{m_{i}}-\overline{\tan \delta_{m}}\right)^{2}} \cdot \sqrt{\sum_{i=1}^{n}\left(\tan \delta_{f_{i}}-\overline{\tan \delta_{f}}\right)^{2}}},
$$

where:

- $\quad \tan \delta_{m}$-loss tangent measured for a specific frequency;

- $\quad \tan \delta_{f}$-loss tangent calculated for a specific frequency based on XY or 2XY model;

- $\quad n$-number of points for which measurements and calculations were carried out.

In our case, the correlation coefficient describes the relationship between the measured curve and the one calculated on the basis of the model. It can take values from -1 to 1 , where 1 means full correlation, zero means no correlation, and -1 means inverse correlation. The correlation coefficient $r$ is a good illustration of the similarity of the shapes 
of the analyzed curves, but it does not illustrate the differences in values. The differences in values are correctly described by the mean of the absolute difference modules $\left(M_{A D M}\right)$.

Tables 4 and 5 present the parameters used in the calculation of the dielectric response $(X / Y$, temperature $T$, conductivity of oil $\delta$, and moisture in paper $M c)$ as well as the correlation coefficients $r$ and the mean of the absolute difference modules $M_{\mathrm{ADM}}$ for the three analyzed bushings, respectively, for the XY (Table 4) and the 2XY models (Table 5).

Table 4. $X Y$ model parameters used in modelling the dielectric response of the tested bushings.

\begin{tabular}{|c|c|c|c|c|c|c|}
\hline \multirow{2}{*}{ № } & \multicolumn{6}{|c|}{ XY Model } \\
\hline & $X / Y, \%$ & $T,{ }^{\circ} \mathrm{C}$ & $\sigma, \mathrm{S} / \mathrm{m}$ & $M c, \%$ & $r$ & $M_{A D M}, \%$ \\
\hline Bushing 1 & $85 / 45$ & 30 & $7.79 \times 10^{-13}$ & 2.3 & 0.980 & 46.5 \\
\hline Bushing 2 & $90 / 0$ & 22 & $2.72 \times 10^{-11}$ & 2.3 & 0.942 & 38.9 \\
\hline Bushing 3 & $74 / 86$ & 25 & $1.69 \times 10^{-12}$ & 1.0 & 0.991 & 5.9 \\
\hline
\end{tabular}

Table 5. $2 X Y$ model parameters used in modelling the dielectric response of the tested bushings.

\begin{tabular}{|c|c|c|c|c|c|c|c|c|c|}
\hline \multirow[b]{2}{*}{ № } & \multicolumn{9}{|c|}{ 2XY Model } \\
\hline & $X_{1} / Y_{1}, \%$ & $X_{2} / Y_{2}, \%$ & $\begin{array}{l}T_{1}, \\
{ }^{\circ} \mathrm{C}\end{array}$ & $\begin{array}{l}T_{2}, \\
{ }^{\circ} \mathrm{C}\end{array}$ & $\begin{array}{c}\sigma_{2} \\
\mathrm{~S} / \mathrm{m}\end{array}$ & $M c_{1}, \%$ & $M c_{2}, \%$ & $r$ & $M_{A D M}, \%$ \\
\hline Bushing 1 & $96 / 2$ & $100 / 100$ & 24 & 43 & $1.87 \times 10^{-11}$ & 2.5 & 2.5 & 0.985 & 14.6 \\
\hline Bushing 2 & $31 / 69$ & $100 / 100$ & 15 & 36 & $1.60 \times 10^{-9}$ & 3.7 & 3.6 & 0.983 & 11.3 \\
\hline Bushing 3 & $94 / 0$ & $98 / 33$ & 18 & 38 & $9.37 \times 10^{-12}$ & 1.0 & 1.0 & 0.999 & 3.2 \\
\hline
\end{tabular}

The parameters with the index 1 presented in Table 5 refer to the air part of the insulator, while parameters with the index 2 refer to the oil part. Table 5 does not provide the oil conductivity for the air part because it is calculated automatically in the program based on the oil conductivity in the oil part, and the temperature difference between the oil part and the air part of the insulator, according to the formulae [16]:

$$
\sigma_{1}=\sigma_{2} \exp \left[\frac{A_{e}}{k} \cdot\left(\frac{1}{273-T_{1}}-\frac{1}{273-T_{2}}\right)\right]
$$

where:

- $\quad \sigma_{1}$-oil conductivity in the air part (at $T_{1}$ temperature);

- $\quad \sigma_{2}$-oil conductivity in the oil part (at $T_{2}$ temperature);

- $\quad A_{e}$-activation energy equal to $0.4 \mathrm{eV}$;

- $\quad k$-Boltzmann constant.

Analyzing the data presented in Figures 13-15, one can see that in each case, the fit of the model curves to the measurement curves is better when the 2XY model is used. It is especially visible for insulators with higher humidity, but also noticeable for dry insulators. The relative differences $(R d)$, correlation coefficients $(r)$, and mean of the absolute difference modules $\left(M_{A D M}\right)$ clearly indicate that the 2XY model better fits the dielectric response of insulators than the classical model.

\section{Conclusions}

The most important conclusion from the research results presented in this article is the need to analyze the dielectric response of bushings, taking into account the axial temperature distribution. During the work life of a bushing, the temperature distribution occurs both in the axial and radial directions. However, measurement can only be performed a few hours after the transformer has been turned off (in particular due to the need to comply with formal procedures, safety procedures, preparation of the workplace, removal of connectors from insulators, etc.). After this time, the temperature distribution in the 
bushing changes and is close to the axial distribution, which can be roughly described. We can distinguish the temperature of the lower part (usually equal to the temperature of the transformer oil in the upper layer) and the temperature of the upper part of bushing in the air.

The laboratory tests performed on a specially prepared measuring stand and the field tests on insulators installed on transformers indicate the influence of the axial temperature distribution on the dielectric response of the bushings. This influence is especially visible for insulators in poor technical condition (those whose insulation has a relatively high water content).

The authors proposed to extend the XY model — which assumes a uniform temperature distribution and is usually used in the analysis of the dielectric response- to the $2 X Y$ model. The 2XY model makes it possible to consider different values of the bushing temperature in its oil and air parts, as well as different water content in its paper insulation and different oil conductivity in these parts.

Comparisons of the dielectric responses calculated with the use of the $X Y$ and $2 X Y$ models show that considering the axial temperature distribution results in a much better fit of the model curves to the measured ones. This fit was assessed using the absolute difference modules $\left(M_{A D M}\right)$ and the correlation coefficient $(r)$. Both of these parameters clearly indicate that the $2 \mathrm{XY}$ model better reflects the measured dielectric response than the $\mathrm{XY}$ model. This better fit is also confirmed by the values of relative differences between the measured and calculated values for both models.

The examples presented in the article show that the use of the $\mathrm{XY}$ model to analyze the dielectric response of insulators with a significant temperature distribution results in an underestimation of the water content in the insulation, which may incorrectly indicate that the insulator is in better condition than it actually is. This effect will especially be noticeable in the case of insulators in poor technical condition, which may lead to leaving such a bushing in operation and, consequently, to a catastrophic failure.

Including the axial temperature distribution in the modeling significantly improved the quality of fitting the dielectric response. However, the authors are aware that in practice, there may be situations in which the proposed $2 \mathrm{XY}$ model will be less effective, e.g., when a radial temperature distribution occurs, or when the surface of the ceramic shield is heavily contaminated.

In the future, the patterns for dielectric response of insulation that can absorb water (for example RIP and RBP), should be created; it will then be possible to conduct tests for those types of insulators.

Author Contributions: Conceptualization, K.W. and J.G.; methodology, K.W. and J.G.; validation, K.W.; formal analysis, K.W. and J.G.; investigation, K.W. and J.G.; resources, K.W. and J.G.; data curation, K.W. and J.G.; writing-original draft preparation, K.W. and J.G.; writing—review and editing, K.W. and J.G.; visualization, K.W. and J.G.; supervision, K.W. All authors have read and agreed to the published version of the manuscript.

Funding: This research was financing from Ministry of Science and Higher Education, Poland, grant number 0711/SBAD/4455.

Institutional Review Board Statement: Not applicable.

Informed Consent Statement: Not applicable.

Data Availability Statement: Not applicable.

Conflicts of Interest: The authors declare no conflict of interest. 


$\begin{array}{lll}\text { Nomenclature } & & \\ & & \\ \text { Variable } & \text { Symbol } & \text { Units } \\ \text { Complex permitivity } & \varepsilon^{*} & \mathrm{~F} / \mathrm{m} \\ \text { Real part of complex permitivity } & \varepsilon^{\prime} & \mathrm{F} / \mathrm{m} \\ \text { Imaginary part of complex permitivity } & \varepsilon^{\prime \prime} & \mathrm{F} / \mathrm{m} \\ \text { Relative content of barriers } & X & \% \\ \text { Relative content of spacers } & Y & \% \\ \text { Loss tangent } & \tan \delta & - \\ \text { Mean of the absolute difference modules } & M_{A D M} & \% \\ \text { Correlation coefficient } & r & - \\ \text { Relative differences } & R d & \% \\ \text { Temperature } & T & { }^{\circ} \mathrm{C} \\ \text { Frequency } & f & \mathrm{~Hz} \\ \text { Voltage } & U & \mathrm{~V} \\ \text { Activation energy } & A_{e} & \mathrm{eV} \\ \text { Participation of the air part in the whole volume of the insulator } & A & \% \\ \text { Conductivity } & \sigma & \mathrm{S} / \mathrm{m} \\ \text { Moisture content in paper } & M c & \%\end{array}$

\section{References}

1. Micafil Transformer Bushings, AirRIP, 2021. Available online: https://www.hitachiabb-powergrids.com/pl/pl/offering/productand-system/transformer-insulation-and-components/bushings/resin-impregnated-paper-rip/ac-bushing-type-airrip-flex (accessed on 30 June 2021).

2. Septyani, H.I.; Arifianto, I.; Purnomoadi, A.P. High voltage transformer bushing problems. In Proceedings of the 2011 International Conference on Electrical Engineering and Informatics, Bandung, Indonesia, 7-19 July 2011; pp. 1-4. [CrossRef]

3. Wankowicz, J.; Bielecki, J.; Szrot, M.; Subocz, J.; Malewski, R. HV Bushing Failure in Service, Diagnostics and Modeling of Oil-type Bushings. In Proceedings of the CIGRE Session, Paris, France, 22-27 August 2010; pp. 1-10.

4. CIGRÉ WG A2.37. Transformer Reliability Survey; CIGRE Brochure: Paris, France, 2015.

5. Chen, M.; Liu, X.; Xu, P.; Wen, T. Local Inter-foil Insulation Deterioration Diagnosis and Simulation of RIP Bushing Based on FDS Method. Cond. Monit. Diagn. (CMD) 2018, 1-5. [CrossRef]

6. Huang, Z.; Fu, M.; Zhuo, R.; Jing, Y.; Luo, Y.; Wang, G.; La, Y.; Dong, X. Research on the Wetting Mechanism of Oil-Paper Insulated Bushings and the Application of FDS Method. In Proceedings of the IEEE Sustainable Power and Energy Conference (iSPEC), Beijing, China, 21-23 November 2019; pp. 1903-1908. [CrossRef]

7. Zhang, L.; Han, Y.; Zhao, H.; Zhang, H.; Zhang, D.; Mu, H. Simulation Study on the FDS Characteristics of Non-uniform Dampened Oil-paper Bushing. In Proceedings of the IEEE International Conference on High Voltage Engineering and Application (ICHVE), Beijing, China, 6-10 September 2020; pp. 1-4. [CrossRef]

8. Long, G.; Mu, H.; Zhang, D.; Li, Y.; Zhang, G. Moisture Location of Oil-Paper Insulated Bushing Based on Polarization and Depolarization Current Analysis. In Proceedings of the IEEE 3rd International Conference on Dielectrics (ICD), Virtual, Valencia, Spain, 5-31 July 2020; pp. 692-695. [CrossRef]

9. Qi, B.; Dai, Q.; Li, C.; Zeng, Z.; Fu, M.; Zhuo, R. The Mechanism and Diagnosis of Insulation Deterioration Caused by Moisture Ingress into Oil-Impregnated Paper Bushing. Energies 2018, 11, 1496. [CrossRef]

10. Yang, F.; Du, L.; Yang, L.; Wei, C.; Wang, Y.; Ran, L.; He, P. A Parameterization Approach for the Dielectric Response Model of Oil Paper Insulation Using FDS Measurements. Energies 2018, 11, 622. [CrossRef]

11. Wei, C.; Liao, C.; Du, L.; Chen, X. Influence of Moisture on Dielectric Responses of Oil-Impregnated Paper Condenser Bushings. In Proceedings of the 5th International Conference on Electric Power Equipment-Switching Technology (ICEPE-ST), Kitakyushu, Japan, 13-16 October 2019; pp. 709-712. [CrossRef]

12. Enciso, L.; Martínez, J.L.; Arce, P. Life expectancy of high voltage bushings based on incipient failure detections: A practical approach. In Proceedings of the 2020 IEEE Electrical Insulation Conference (EIC), Knoxville, TN, USA, 22 June-3 July 2020 ; pp. 325-328. [CrossRef]

13. Buchacz, J.; Cichon, A.; Skubis, J. Detection of conductive layers short circuit in HV condenser bushings using Frequency Domain Spectroscopy. IEEE Trans. Dielectr. Electr. Insul. 2017, 24, 552-558. [CrossRef]

14. Subocz, J.; Mrozik, A.; Bohatyrewicz, P.; Zenker, M. Condition Assessment of HV Bushings with Solid Insulation based on the SVM and the FDS Methods. Energies 2020, 13, 853. [CrossRef]

15. Standard No: PN-EN 60584-1:2014-04. In Thermocouples_Part 1: EMF Specifications and Tolerances; PKN: Warsaw, Poland, 2014.

16. Jonscher, A.K. Dielectric relaxation in solids. J. Phys. D Appl. Phys. 1999, 32, 57-70. Available online: https://iopscience.iop.org/ article/10.1088/0022-3727/32/14/201 (accessed on 30 June 2021). [CrossRef] 
17. Dielectric Frequency Response (DFR) Task Force-Final Report. IEEE Transformers Committee, 07 June 2012. Available online: https:/ / grouper.ieee.org/groups//transformers/subcommittees/dielectric_test/F13-C57.161-DFR-TF-Final\%20Report. pdf (accessed on 30 June 2021).

18. Liu, J.; Fan, X.; Zhang, Y.; Zheng, H.; Yao, H.; Zhang, C.; Zhang, Y.; Li, D. A Novel Universal Approach for Temperature Correction on Frequency Domain Spectroscopy Curve of Transformer Polymer Insulation. Polymers 2019, 11, 1126. [CrossRef] [PubMed]

19. Du, Y.; Yang, L.; Liu, X.; Wang, Y.; Gao, J.; Yao, R. Effect of moisture and thermal degradation on the activation energy of oil-paper insulation in frequency domain spectroscopy measurement. IET Gener. Transm. Distrib. 2016, 10, 2042-2049. Available online: https: / /ietresearch.onlinelibrary.wiley.com/doi/10.1049/iet-gtd.2015.0946 (accessed on 30 June 2021).

20. Ekanayake, C.; Gubanski, S.M.; Graczkowski, A.; Walczak, K. Frequency response of oil impregnated pressboard and paper samples for estimating moisture in transformer insulation. IEEE Trans. Power Deliv. 2006, 21, 1309-1317. [CrossRef]

21. Liu, J.; Fan, X.; Zhang, Y.; Zheng, H.; Jiao, J. Temperature correction to dielectric modulus and activation energy prediction of oil-immersed cellulose insulation. IEEE Trans. Dielectr. Electr. Insul. 2020, 27, 956-963. [CrossRef]

22. Gielniak, J.; Graczkowski, A.; Gubanski, S.; Moranda, H.; Mościcka-Grzesiak, H.; Walczak, K. Influence of thermal ageing on dielectric response of oil-paper insulation. Mater. Sci.-Poland 2009, 27, 1199-1205.

23. Ekanayake, C.; Graczkowski, A.; Walczak, K.; Gubanski, S.M. Dielectric spectroscopy measurements on oil impregnated paper/pressboard samples. In Proceedings of the International Conference APTADM, Wroclaw, Poland, 15-17 September 2004; pp. 113-120.

24. Gielniak, J.; Ekanayake, C.; Walczak, K.; Graczkowski, A.; Gubanski, S.M. Dielectric response of new and aged transformer pressboard in dry and wet states. In Proceedings of the International Symposium on Electrical Insulating Materials ISEIM 2005, Kitakyushu, Japan, 5-9 June 2005; Volume 2, pp. 386-389. [CrossRef]

25. Xie, J.; Dong, M.; Yu, B.; Hu, Y.; Yang, K.; Xia, C. Physical Model for Frequency Domain Spectroscopy of Oil-Paper Insulation in a Wide Temperature Range by a Novel Analysis Approach. Energies 2020, 13, 4530. [CrossRef]

26. Gafvert, U.; Frimpong, G.; Fuhr, J. Modelling of Dielectric Measurements on Power Transformers. In Proceedings of the CIGRE Session, Paris, France, 1998; pp. 15-103. Available online: https:/ /e-cigre.org/publication/SESSION1998-1998-cigre-session (accessed on 3 July 2021).

27. Gafvert, U.; Adeen, L.; Tapper, M.; Ghasemi, P.; Jonsson, B. Dielectric Spectroscopy in Time and Frequency Domain Applied to Diagnostics of Power Transformers. In Proceedings of the International Conference on Properties and Applications of Dielectric Materials, Xi'an, China, 21-26 June 2000; pp. 825-830. [CrossRef]

28. Gielniak, J.; Graczkowski, A.; Moranda, H.; Przybylek, P.; Walczak, K.; Nadolny, Z.; Moscicka-Grzesiak, H.; Feser, K.; Gubanski, S.M. Moisture in cellulose insulation of power transformers-statistics. IEEE Trans. Dielectr. Electr. Insul. 2003, 20, 982. [CrossRef]

29. Gielniak, J. Influence of geometrical parameters and temperature of oil-paper insulation on analysis results by means dielectric response method. Przeglad Elektrotechniczny 2010, 86, 220-222.

30. Framework Instruction for Operation of Transformers; Energopomiar-Elektryka: Gliwice, Poland, 2012.

31. Johnson, R.; Kuby, P.J. Elementary Statistics, 11th ed.; Cengage Learning: Boston, MA, USA, 2011. 